\title{
The Profile of Genetic Mutations in Papillary Thyroid Cancer Detected by Whole Exome Sequencing
}

\author{
Yi Fang ${ }^{\mathrm{a}, \mathrm{b}}$ Xiao $\mathrm{Ma}^{\mathrm{c}}$ Jing Zeng ${ }^{\mathrm{b}}$ Yanwen Jin ${ }^{\mathrm{a}}$ Yong $\mathrm{Hu}^{\mathrm{a}} \quad$ Jinjing Wang ${ }^{\mathrm{b}}$ \\ Ran Liu ${ }^{b}$ Cheng Cao
}

aBeijing Institute of Biotechnology, Beijing, 'bendocrinology Department, 307 hospital, PLA, Beijing, cKey Laboratory of Carcinogenesis and Translational Research, Department of Head and Neck, Perking University Cancer Hospital and Institute, Beijing, China

\section{Key Words}

Papillary thyroid cancer $\cdot$ Next-generation sequencing - Whole exome sequencing $\cdot$ Sanger sequencing $\cdot$ Genetic mutations

\begin{abstract}
Background/Aims: The purpose of the study was to investigate the altered driver genes and signal pathways during progression of papillary thyroid cancer (PTC) via next-generation sequencing technology. Methods: The DNA samples for whole exome sequencing (WES) analyses were extracted from 11 PTC tissues and adjacent normal tissues samples. Direct Sanger sequencing was applied to validate the identified mutations. Results: Among the 11 pairs of tissues specimens, 299 single nucleotide variants (SNVs) in 75 genes were identified. The most common pattern of base pair substitutions was $T: A>C: G(49.83 \%)$, followed by $C: G>T: A(18.06 \%)$ and $C: G>G: C(15.05 \%)$. The altered genes were mainly implicated in MAPK (mitogen-activated protein kinase), PPAR (peroxisome proliferator-activated receptors), and p53 signaling pathways. In addition, 12 novel identified driver genes were validated by Sanger sequencing. The mutations of FAM133A, DPCR1, JAK1, C10orf10, EPB41L3, GPRASP1 and IWS1 exhibited in multiple PTC cases. Furthermore, the PTC cases exhibited individual mutational signature, even the same gene might present different mutational status in different cases. Conclusion: Multiple PTC-related somatic mutations and signal pathways are identified via WES and Sanger sequencing methods. The novel identified mutations in genes such as FAM133A, DPCR1, and JAK1 may be potential therapeutic targets for PTC patients.
\end{abstract}




\section{Cellular Physiology Cell Physiol Biochem 2018;50:169-178 \begin{tabular}{ll|l} 
and Biochemistry Published online: 3 October 2018 & $\begin{array}{l}\text { (c) } 2018 \text { The Author(s). Published by S. Karger AG, Basel } \\
\text { www.karger.com/cpb }\end{array}$
\end{tabular}}

Fang et al.: Whole Exome Sequencing for Papillary Thyroid Cancer

\section{Introduction}

Thyroid cancer is a common endocrine malignancy, with rapidly increased morbidity during the last few decades [1]. The incidence rate of thyroid cancer presents distinct age and gender diversities, and its morbidity is significantly higher in women than that in men [2]. Papillary thyroid carcinoma (PTC) represents the most common histological subtype of thyroid cancer, accounting for about $75-85 \%$ of the cases [3]. Until now, surgical strategy is the major treatment for patients with thyroid cancer, due to its high resistance to standard chemotherapy [4]. However, the extensive resection, postoperative recurrence and metastasis may lead to limited therapeutic effects and poor outcomes [5]. The reliable tools are urgently needed to predict tumor progression and prognosis for patients with PTC. PTC is a complex disease, and both genetic and environmental factors such as iodine intake and radiation exposure are implicated in etiology of the cancer [6, 7]. Growing evidences have demonstrated that genetic factors play an important role in PTC development and treatments $[8,9]$. Until now the mechanisms underlying the tumorigenesis of PTC still remains unclear, and prediction of disease progression is a great challenge for PTC cases [10].

Recent progress in sequencing techniques may provide a promising way to identify the somatic mutations and altered signal pathways during progression of PTC. Whole exome sequencing (WES) is an effective technology to identify the mutations in the exome regions using the next-generation sequencing, becoming a commonly used approach to investigate the genetic alteration in diseases, like cancer [11]. In the previous investigations, the success application of WES was reported in various cancers. For example, Li et al. performed WES combined with genome sequencing method on Epstein-Barr virus (EBV)-positive nasopharyngeal carcinoma (NPC) tissues specimens, and they observed the mutations of multiple negative regulators in NF- $\mathrm{kB}$ pathway such as CYLD, TRAF3, NFKBIA and NLRC5, suggesting the functional roles of NF- $\mathrm{BB}$ pathway in tumorigenesis of NPC [12]. Guo and colleagues identified 54 single nucleotide polymorphisms (SNPs) and 41 indels of prominent variations in solid pseudopapillary tumor of the pancreas, revealing their involvements in molecular mechanism of the cancer [13]. The application of WES in thyroid cancer was also reported in the previous tumor researches. Lu et al. observed that the mutations status of driver genes were significantly different among patients with multifocal papillary thyroid cancer (MPTC) via WES and targeted region sequencing methods [14]. Based on the related researches, we speculated that WES might be a promising approach to identify the mutational genes and pathways in progression of PTC, which might provide a new insight into the etiology of the malignant disease.

In this study, we performed WES combined with Sanger sequencing technology to investigate the profile of genetic alterations in 11 PTC cases. The genetic mutations and altered pathways during progression of PTC were characterized in order to explore novel PTC-related genes which might be applied for individual treatments of PTC.

\section{Materials and Methods}

\section{Study population and specimens collection}

In the current study, PTC tissues and adjacent normal tissues specimens were collected from 11 patients who underwent thyroid surgery in 307 hospital, PLA. The tissues samples were immediately frozen in liquid nitrogen, and then stored at $-80^{\circ} \mathrm{C}$ for further analyses. All of the patients were pathologically diagnosed with PTC according to World Health Organization classification, and the tissues specimens were reviewed by two pathologists. In addition, fasting blood specimens were also collected from the patients before surgeries to serve as control. None of the patients had received radioactive iodine treatment or other therapies before samples collection. The baseline characteristics of the patients were collected from the clinical records and summarized in Table 1. The study protocols were approved by the Ethic Committee of the hospital. All the patients or their family signed the informed consents in advance. 


\section{Cellular Physiology Cell Physiol Biochem 2018;50:169-178 \begin{tabular}{l|l|l} 
and Biochemistry $10.1159 / 000493966$ & $\begin{array}{l}\text { C } 2018 \text { The Author(s). Published by S. Karger AG, Basel } \\
\text { www.karger.com/cpb }\end{array}$ \\
\hline
\end{tabular}}

Fang et al.: Whole Exome Sequencing for Papillary Thyroid Cancer

Genomic DNA extraction and construction of genomic DNA libraries

Genomic DNA was extracted from the 11 pairs of PTC tissues and corresponding noncancerous tissues specimens using a DNeasy Blood \& Tissue Kit (Qiagen, Hilden, Germany) following the manufacturer's instruction. The genomic DNA libraries was prepared by the IlluminaTruSeq DNA Sample Prep Guide (Illumina, San Diego, CA, USA). In briefly, the genomic DNA was randomly fragmented to $150-200 \mathrm{bp}$ in size by a Covaris sonicator (Covaris, Woburn, MA). A PCR purification kit (catalog no. 28104; QIAGEN, Valencia, CA) was applied to purify the DNA fragments. Subsequently, the adaptors were ligated to the fragments at both ends. The Agecoure AMPure SPRI beads (Beckmancoulter, Brea, CA, USA) was performed to purify the adapter-ligated templates. For enrichment, the DNA fragments were amplified by ligated-mediated PCR amplification system according to the Illumina's suggesting protocols (Illumina, San Diego, CA). After amplification and purification, the quality of the libraries was detected by Agilent 2100 Bioanalyzer (Agilent Technologies, San Jose, CA, USA).

Exome capture and sequencing

Exome was captured by Agilent SureSelect paired-end version 2.0 human exome kit (Agilent, Santa Clara, CA) following the instruction of the manufactures. Then Illumina HiSeq2000 Genome Analyzer platform (Illumina, San Diego, CA) was used for exome sequencing. The base calling was performed with Illumina basecalling Software 1.7, generating $100 \mathrm{bp}$ paired end reads.

\section{Somatic variations validation}

Sanger sequencing technique was carried out to verify the somatic mutations of interest in each diseased tissue sample. PCR reaction was performed in a 2720 Thermal Cycler (Applied Biosystems, Foster City, CA, USA) using Platinum Taq (Invitrogen, Foster City, CA, USA). After purification, the products were sequenced by Terminator v3.0 cycle sequencing reagents (Applied Biosystems, Foster City, CA, USA), and the results were analyzed on ABIPRISM 3100 automated sequencer (Applied Biosystems, Foster City, CA, USA).

\section{Bioinformatics analyses}

Illumina basecalling Software 1.7 (Illumina, San Diego, CA) was applied for base calling, generating $100 \mathrm{bp}$ paired end reads. The reads were then aligned to the human reference genome (UCSC hg 19) using Burrows-Wheeler Aligner method with default parameters [15]. VarScan 2 method was used to analyze somatic mutations [16]. Single nucleotide variants (SNVs) and insertions and deletions mutations were annotated by ANNOVAR tool (http://www.openbioinformatics.org/annovar/) [17, 18]. MuSiC software (http://www.broadinstitute.org/cancer/cga/mutsig) was applied to identify the significantly mutated genes, and annotate the related pathways [19-21].

\section{Results}

\section{Baseline characteristics of the study population}

A total of 11 eligible patients were recruited in the present study. Nine of the patients were females, and their average age was $42.82 \pm 14.11$ years. Four of the patients were diagnosed with TI stage, six patients were at TIII stage, and the remaining one patient was at TIVa stage. In addition, seven of the patients presented lymph node metastasis. The clinical characteristics of the study population was summarized in Table 1. 
Table 2. The exome capture profiles in each sample

\begin{tabular}{lcccc}
\hline $\begin{array}{l}\text { Sample } \\
\text { ID }\end{array}$ & $\begin{array}{c}\text { Coverage of target } \\
\text { region }\end{array}$ & $\begin{array}{c}\text { Fraction of effective sequence on } \\
\text { target region }\end{array}$ & $\begin{array}{c}\text { Coverage of flanking } \\
\text { region }\end{array}$ & $\begin{array}{c}\text { Fraction of effective sequence on } \\
\text { flanking region }\end{array}$ \\
\hline R02_N & $99.50 \%$ & $96.47 \%$ & $7.43 \%$ & $0.23 \%$ \\
R02_T & $99.46 \%$ & $96.05 \%$ & $7.82 \%$ & $0.24 \%$ \\
R03_N & $99.36 \%$ & $95.79 \%$ & $7.12 \%$ & $0.27 \%$ \\
R03_T & $99.29 \%$ & $94.54 \%$ & $6.81 \%$ & $0.29 \%$ \\
R04_N & $99.21 \%$ & $95.82 \%$ & $6.20 \%$ & $0.27 \%$ \\
R04_T & $99.23 \%$ & $95.62 \%$ & $6.69 \%$ & $0.27 \%$ \\
R05_N & $99.37 \%$ & $95.01 \%$ & $8.00 \%$ & $0.32 \%$ \\
R05_T & $99.36 \%$ & $93.47 \%$ & $9.29 \%$ & $0.35 \%$ \\
R08_N & $99.48 \%$ & $95.00 \%$ & $8.10 \%$ & $0.35 \%$ \\
R08_T & $99.24 \%$ & $94.37 \%$ & $5.05 \%$ & $0.37 \%$ \\
R12_N & $99.33 \%$ & $95.49 \%$ & $6.02 \%$ & $0.30 \%$ \\
R12_T & $99.48 \%$ & $92.68 \%$ & $13.16 \%$ & $0.38 \%$ \\
R14_N & $99.47 \%$ & $95.32 \%$ & $8.23 \%$ & $0.32 \%$ \\
R14_T & $99.44 \%$ & $94.84 \%$ & $8.05 \%$ & $0.32 \%$ \\
R15_N & $99.47 \%$ & $94.36 \%$ & $10.85 \%$ & $0.36 \%$ \\
R15_T & $99.46 \%$ & $93.06 \%$ & $11.34 \%$ & $0.38 \%$ \\
R16_N & $99.38 \%$ & $94.71 \%$ & $8.23 \%$ & $0.35 \%$ \\
R16_T & $99.38 \%$ & $93.28 \%$ & $9.77 \%$ & $0.37 \%$ \\
R17_N & $99.65 \%$ & $94.28 \%$ & $11.83 \%$ & $0.37 \%$ \\
R17_T & $99.60 \%$ & $92.62 \%$ & $10.16 \%$ & $0.39 \%$ \\
R22_N & $99.49 \%$ & $94.16 \%$ & $10.43 \%$ & $0.38 \%$ \\
R22_T & $99.49 \%$ & $93.85 \%$ & $10.62 \%$ & $0.37 \%$ \\
\hline
\end{tabular}

\section{Whole} sequencing

DNA samples used for WES were purified from 11 PTC tissues and adjacent non-cancerous tissues specimens, as well as corresponding blood samples. A total of $181.7 \mathrm{G}$ of high quality exome sequences data were generated. Moreover, about $98 \%$ of the sequence reads were mapped to the human reference genome (UCSC hg 19). The coverage of target region was more than 99\% in each sample, and the fraction of effective sequence on target region was over $92 \%$ in all the reads. The detailed information of exome capture in each sample was summarized in Table 2. The average sequencing depth of the target region was over 100X among twenty of the samples (Fig. 1).
Fig. 1. The average sequencing depth in each sample. The average sequencing depth of the target region was over $100 \mathrm{X}$ in twenty of the 11 pairs of samples.

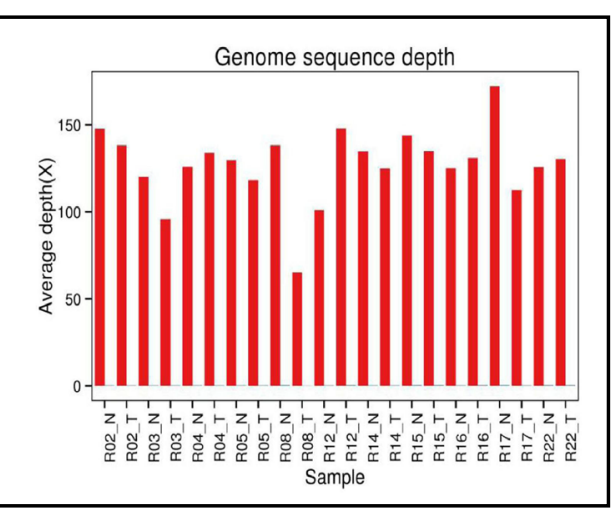

Fig. 2. The LOH (loss of heterozygosity) profile of somatic mutations in each case. A total of 33 mutations caused by $\mathrm{LOH}$ were identified in the 11 PTC samples, and Sample R08 presented high frequency of LOH. All the mutations were nonsynonymous SNV,

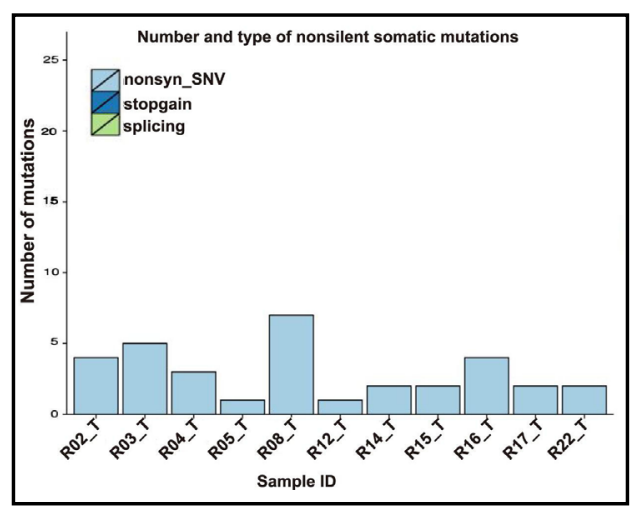
and no stopgain or splicining were observed. 
Fig. 3. The distribution of base pair substitutions in each case. There were six patterns of base pair substitutions among the identified SNVs, the most common base pair substitutions was $\mathrm{T}: \mathrm{A}>\mathrm{C}: \mathrm{G}$, accounting for $49.83 \%$, followed by $\mathrm{C}: \mathrm{G}>\mathrm{T}: \mathrm{A}$ (18.06\%) and C:G>G:C (15.05\%).
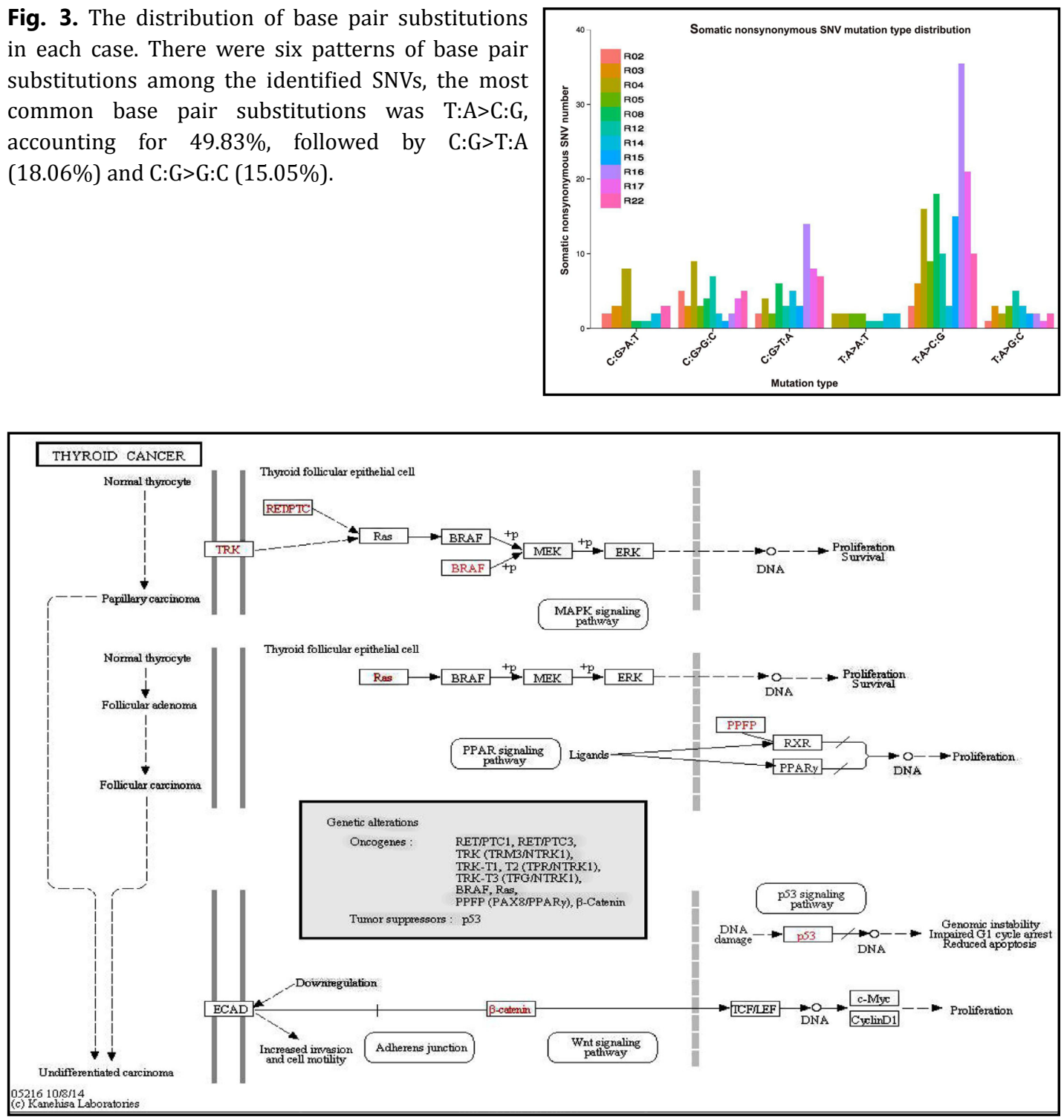

Fig. 4. The enriched biological processes analyses based on the identified somatic mutations. KEGG pathway analyses demonstrated that the mutational genes were mainly implicated in MAPK, PPAR, and p53 signal pathways, suggesting their functional roles in tumorigenesis of PTC.

Among the 11 pairs tissues specimens, a total of 299 SNVs in 75 genes were identified. LOH (Loss of heterozygosity) represents a common event in tumorigenesis. In this study, 33 mutations caused by LOH were identified. We found that nonsynonymous SNV was the major reason for LOH among the detected samples (Fig. 2).

In addition, we also investigated the distribution of nonsynonymous SNV type in the sequencing samples. The most common base pair substitutions was $\mathrm{T}: \mathrm{A}>\mathrm{C}: \mathrm{G}$, accounting for 49.83\%, followed by C:G>T:A (18.06\%) and C:G>G:C (15.05\%) (Fig. 3).

Driver gene mutations and enriched biological pathways analyses in PTC

A total 75 altered genes including 11 commonly altered genes and 64 novel driver genes were identified in the current study. The most commonly altered genes included the oncogenes PET/PTC1, PET/PTC3, TRK (TRM3/NTRK1), TRK-T3 (TFG/NTRK1), BRAF, Ras, $P P F P$, and $\beta$-Catenin, as well as the tumor suppressor $p 53$. The enriched biological processes analyses were performed based on the identified somatic mutations. According to KEGG 


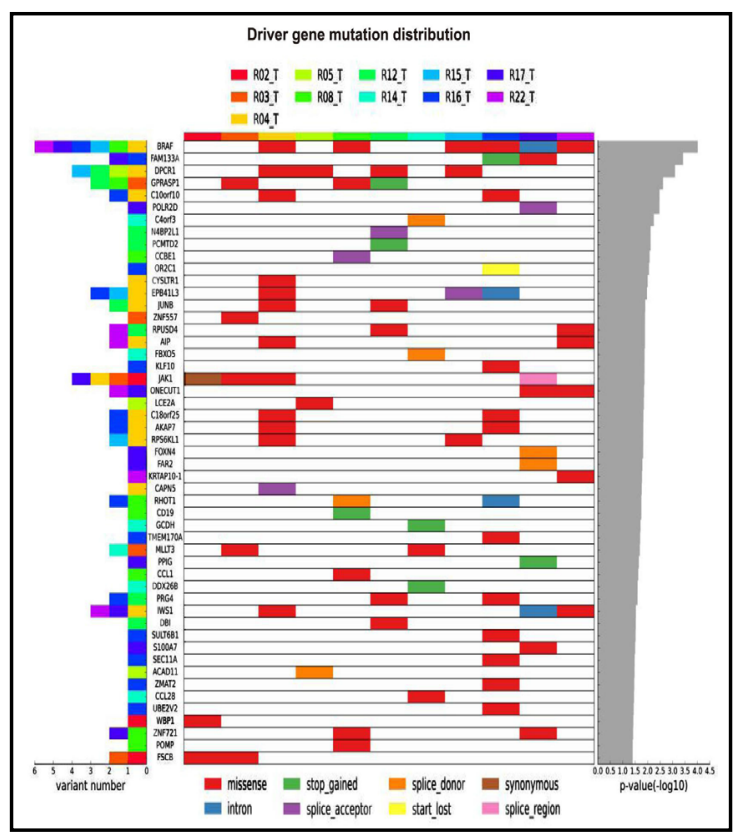

Fig. 5. The distribution of the novel driver gene mutations in each case. A total of 64 novel altered genes were identified by WES in the 11 pairs of PTC tissue specimens. The left of the figure described the variant numbers of the somatic mutations in each case. The middle of the figure described the mutational types in different cases.

Table 3. Summary of the individuals mutations and altered proteins in the 11 thyroid cancer specimens verified by direct Sanger sequencing. *, represented stop codon which was caused by stopgain mutation

\begin{tabular}{|c|c|c|c|c|c|}
\hline Sample ID & Gene & Chromosome & Position & Nucleotide change & $\begin{array}{l}\text { Protein } \\
\text { change }\end{array}$ \\
\hline R17 & FAM133A & ChrX & 92964956 & $\mathrm{G}>\mathrm{A}$ & R180G \\
\hline R16 & FAM133A & ChrX & 92964970 & $A>C$ & Y $184^{*}$ \\
\hline R15 & DPCR1 & Chr6 & 30918160 & $A>G$ & G640E \\
\hline R12 & DPCR1 & Chr6 & 30919186 & $\mathrm{G}>\mathrm{A}$ & E982G \\
\hline R12 & DPCR1 & Chr6 & 30919278 & $\mathrm{G}>\mathrm{A}$ & T1013A \\
\hline R05 & DPCR1 & Chr6 & 30917421 & $\mathrm{~T}>\mathrm{C}$ & P394S \\
\hline R04 & DPCR1 & Chr6 & 30917388 & $A>C$ & H383N \\
\hline R04 & DPCR1 & Chr6 & 30917391 & $A>G$ & G384R \\
\hline R12 & GPRASP1 & ChrX & 101909895 & $\mathrm{~T}>\mathrm{A}$ & K352* \\
\hline R08 & GPRASP1 & ChrX & 101912332 & $\mathrm{G}>\mathrm{A}$ & E1164G \\
\hline R03 & GPRASP1 & ChrX & 101912332 & $\mathrm{G}>\mathrm{A}$ & E1164G \\
\hline R16 & C10orf10 & Chr10 & 45473156 & $\mathrm{G}>\mathrm{A}$ & L108P \\
\hline R04 & C10orf10 & Chr10 & 45473044 & $G>C$ & M145I \\
\hline R17 & POLR2D & Chr2 & 128610681 & $\mathrm{C}>\mathrm{T}$ & 25 \\
\hline R14 & C4orf3 & Chr4 & 120221489 & $\mathrm{G}>\mathrm{A}$ & 200 \\
\hline R12 & N4BP2L1 & Chr13 & 32977339 & $\mathrm{C}>\mathrm{T}$ & $\_158_{-}$ \\
\hline R12 & PCMTD2 & Chr20 & 62904633 & $\mathrm{~T}>\mathrm{A}$ & K256* \\
\hline R08 & CCBE1 & Chr18 & 57147472 & $\mathrm{C}>\mathrm{T}$ & _.71_ \\
\hline R15 & EPB41L3 & Chr18 & 5394793 & $\mathrm{~T}>\mathrm{C}$ & _1052_ \\
\hline R04 & EPB41L3 & Chr18 & 5416346 & $\mathrm{G}>\mathrm{A}$ & L513S \\
\hline R17 & JAK1 & Chr1 & 65330657 & $\mathrm{C}>\mathrm{T}$ & 331 \\
\hline R04 & JAK1 & Chr1 & 65330630 & $A>T$ & N339I \\
\hline R03 & JAK1 & Chr1 & 65339111 & $\mathrm{C}>\mathrm{T}$ & $\mathrm{K} 142 \mathrm{R}$ \\
\hline $\mathrm{R} 02$ & JAK1 & Chr1 & 65305400 & $A>G$ & L910L \\
\hline R22 & IWS1 & Chr2 & 128238682 & $\mathrm{C}>\mathrm{T}$ & K800E \\
\hline R04 & IWS1 & Chr2 & 128238682 & $\mathrm{C}>\mathrm{T}$ & $\mathrm{K} 800 \mathrm{E}$ \\
\hline
\end{tabular}

analyses, the mutated genes were mainly implicated in MAPK (mitogen-activated protein kinase), PPAR (peroxisome proliferator-activated receptors), and p53 signaling pathways, suggesting the functional roles of these pathways in the pathology of PTC (Fig. 4).

\section{Driver gene mutations verified by direct Sanger sequencing}

The novel identified driver genes and their mutation types in the 11 pairs tissues specimens were shown in Fig. 5. In addition, 12 of the mutational genes including FAM133A, DPCR1, GPRASP1, C10orf10, POLR2D, C4orf3, N4BP2L1, PCMTD2, CCBE1, EPB41L3, JAK1, IWS1 were verified by direct Sanger sequencing method. Among them, the mutations of FAM133A, DPCR1, JAK1, C10orf10, EPB41L3, GPRASP1, and IWS1 exhibited in multiple thyroid cancer specimens. Furthermore, the genes might present distinct alterations in different tissues specimens. For instance, in R17 case, FAM133A exhibited a mutation of $\mathrm{G}>\mathrm{A}$ at the position of 92964956, while in R16 case a substitution of $A>C$ at the position of 92964970 was observed in the gene. The detailed information of individuals mutations of the 12 genes in the 11 tissues specimens were summarized in Table 3.

\section{Discussion}

PTC, arising from follicular epithelium, represents the major histological type of thyroid cancer [22]. Surgical strategy and radioiodine are accepted as the first-line treatment for patients with PTC, contributing to improved quality of life and prolonged survival time [23]. However, there are still a few of patients will develop recurrence and metastasis, leading to therapeutic failures and dismal outcomes [24]. The heterogenous biological behaviors of PTC may be attributed to the diverse genetic backgrounds and molecular mutations [25]. With the development of sequencing technique, WES can identify the mutational genes and signal pathways during tumorigenesis, which may provide 
a new way to investigate the molecular pathogenesis of PTC. For example, in the study of Siraj AK et al., they suggested a previously unknown role of thyroglobulin (TG) somatic mutations in the pathogenesis of PTC [26]. Pan et al. found a exome mutational spectrum of PTC in the Chinese population and highlights lncRNA GAS8-AS1 and LPAR4 as potential diagnostic and therapeutic targets [27]. In the current study, we performed WES technology on 11 pairs PTC tissues samples to investigate the somatic variations during tumorigenesis of PTC. Analysis results revealed that multiple protein-coding related mutations were involved in the development and progression of PTC. Moreover, the mutational signature was distinct in each case. In addition to the frequently mutational genes such as PET/PTC1, PET/PTC3, TRK, TRK-T3 (TFG/NTRK1), BRAF, Ras, PPFP, and $\beta$-Catenin, 64 novel altered genes were also observed in the present study, suggesting their potential function in progression of the malignant disease.

In this study, we found that the base pair substitutions presented six patterns in PTC cases, including $C: G>A: T, C: G>G: C, C: G>T: A, T: A>A: T, T: A>C: G, T: A>G: C$, and the most common patterns was $\mathrm{T}: \mathrm{A}>\mathrm{C}: \mathrm{G}$, followed by $\mathrm{C}: \mathrm{G}>\mathrm{T}: \mathrm{A}$ and $\mathrm{C}: \mathrm{G}>\mathrm{G}: \mathrm{C}$. Agrawal et al. found that $\mathrm{C}: \mathrm{G}>\mathrm{T}: \mathrm{A}$ was the most commonly observed pattern of base pair substitutions in patients with medullary thyroid cancer (MTC) via WES method [28]. The different patterns of base pair substitutions might be responsible for the diverse histological features between PTC and MTC. However, a study based on the WES results of 91 pairs of PTC samples demonstrated that $\mathrm{C}>\mathrm{T} / \mathrm{G}>\mathrm{A}$ substitution was the most common pattern in somatic mutations [29]. Several reasons might contribute to the discrepancy, such as the relatively small sample size, the differences between the study population, and the differences between the WES protocols and the analysis methods. Further researches were required to address the issues.

Development and progression of PTC are considered to be the results of the accumulation of genetic and epigenetic alterations. BRAF is the most common mutation in PTC, and its variations may active the MAPK signal pathway, thus promoting the aggressive progression of PTC [30]. It was reported that the prevalence of $B R A F$ mutations was $30-80 \%$ [31]. In the present study, the mutations of $B R A F$ gene were observed in $54.54 \%$ PTC cases. In addition, the common cancer-related oncogenes such as PET/PTC1, PET/PTC3, TRK (TRM3/NTRK1), TRK-T3 (TFG/NTRK1), BRAF, Ras, PPFP, $\beta$-Catenin and the tumor suppressor $p 53$ also exhibited mutations in PTC cases. Moreover, enriched biological process based on the observed somatic variations demonstrated that the altered genes mainly influenced MAPK, PPAR, and p53 signal pathways. The mentioned three signal pathways played important roles in regulation of cell proliferation, cell cycle, and apoptosis. The function of MAPK and p53 signal pathways in progression of PTC had been reported in a variety of studies [32-34]. It was reported that the activation of MAPK was the primary mechanism for initiation of PTC [20]. The function of PPAR pathway was rarely reported in PTC. PPAR pathway was composed by a group of nuclear receptors which played pivotal roles in cellular differentiation, development and lipid metabolism [35]. The abnormal activation of the signal way implicated with tumorigenesis of bladder cancer, esophageal cancer, follicular thyroid cancers, etc [36-38]. In this study, we found that PPAR signal pathway was involved in the progression of PTC. The results might demonstrated that the frequently mutated signal pathway in other types of cancer might also take part in the carcinogenesis of PTC.

Driver genes can facilitate aggressive growth and metastasis of malignancies. Identification of novel cancer-related driver genes may provide new targets for treatments of cancers. In this study, besides the commonly observed driver genes, a total of 64 novel driver genes were also observed. Sanger sequencing method was applied to identify 12 of the the novel identified somatic mutations, including FAM133A, DPCR1, GPRASP1, C10orf10, POLR2D, C4orf3, N4BP2L1, PCMTD2, CCBE1, EPB41L3, JAK1, IWS1. The mutations of FAM133A, DPCR1, JAK1, C10orf10, EPB41L3, GPRASP1, and IWS1 were observed in multiple cases, even the same genes might present diverse mutational status in different cases. The results might explain the individuals differences in PTC patients, and the related genes held the potential to serve as targets for individuals treatments. In the previous studies, a number of potential driver genes were also found in other subtypes of thyroid cancer through

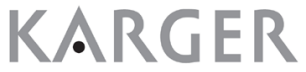




\section{Cellular Physiology Cell Physiol Biochem 2018;50:169-178 \begin{tabular}{l|l|l} 
and Biochemistry 10.1159/000493966 & $\begin{array}{l}\text { (c) } 2018 \text { The Author(s). Published by S. Karger AG, Basel } \\
\text { www.karger.com/cpb }\end{array}$
\end{tabular}}

Fang et al.: Whole Exome Sequencing for Papillary Thyroid Cancer

sequencing technologies. Kunstman et al. investigated the mutational status of 22 anaplastic thyroid cancer (ATC) cases and 4 cell lines using WES method. They found that EIF1AX, NF1, $E R B B 2$ and MTOR might be potential novel drivers of tumor differentiation in the disease [39]. Jeon et al. identified three novel driver genes in ATC via WES combined with direct sequencing: NF2, KMT2D and PKHD1. Furthermore, the mutational status of KMT2D were significantly associated with survival of the patients [40]. The different mutational profiles of driver genes between the subtypes of thyroid cancer might explain the heterogeneity of thyroid cancer, as well as the individual differences. Therefore, application of direct Sanger sequencing technology in more samples could provide new insight into the heterogeneity of malignancy that might contribute to the individual treatments.

Despite of the encouraging results obtained in our study, there were still several limitations. Firstly, due to the limited study time, the sample size in our study was relatively small that might cause bias to the final results. Second, in this study we only compared the mutational patterns between PTC tissues and non-cancerous samples, however, the driver genes associated with grade or metastasis of PTC were not explored. Third, in our study, we only identify PTC-related driven genes, but their functional roles as well as the corresponding molecular mechanisms remained unclear. Further investigations with a larger sample size will be required to address the issues.

In conclusion, WES combined with direct Sanger sequencing method may be a promising approach to investigate the mutational landscape during tumorigenesis of PTC. The enriched biological processes analyses based on the identified altered genes suggest that MAPK, PPAR, and p53 signal pathways are implicated in development and progression of PTC. The mutational signature of the novel identified genes is distinct in each case which may have the ability to serve as targets for individual treatments in PTC patients.

\section{Disclosure Statement}

The authors declare to have no competing interests.

\section{References}

1 Kang JB, Kim EY, Park YL, Park CH, Yun JS: A comparison of postoperative pain after conventional open thyroidectomy and single-incision, gasless, endoscopic transaxillary thyroidectomy: a single institute prospective study. Ann Surg Treat Res 2017;92:9-14.

-2 Siegel RL, Miller KD, Jemal A: Cancer Statistics, 2017. CA Cancer J Clin 2017;67:7-30.

-3 Sharma C: An analysis of trends of incidence and cytohistological correlation of papillary carcinoma of the thyroid gland with evaluation of discordant cases. J Cytol 2016;33:192-198.

4 Rowe CW, Murray K, Woods A, Gupta S, Smith R, Wynne K: Management of metastatic thyroid cancer in pregnancy: risk and uncertainty. Endocrinol Diabetes Metab Case Rep 2016;2016:pii:16-0071.

5 Kulbakin D, Chekalkin T, Muhamedov M, Choynzonov E, Kang JH, Kang SB, Gunther V: Sparing Surgery for the Successful Treatment of Thyroid Papillary Carcinoma Invading the Trachea: A Case Report. Case Rep Oncol 2016;9:772-780.

6 Meinhold CL, Ron E, Schonfeld SJ, Alexander BH, Freedman DM, Linet MS, Berrington de Gonzalez A: Nonradiation risk factors for thyroid cancer in the US Radiologic Technologists Study. Am J Epidemiol 2010;171:242-252.

7 Ning L, Rao W, Yu Y, Liu X, Pan Y, Ma Y, Liu R, Zhang S, Sun H, Yu Q: Association between the KRAS Gene Polymorphisms and Papillary Thyroid Carcinoma in a Chinese Han Population. J Cancer 2016;7:2420-2426.

8 Zhang Q, Liu SZ, Guan YX, Chen QJ, Zhu QY: Meta-Analyses of Association Between BRAF(V600E) Mutation and Clinicopathological Features of Papillary Thyroid Carcinoma. Cell Physiol Biochem 2016;38:763-776.

-9 Liu L, Li D, Chen Z, Yang J, Ma Y, Cai H, Shan C, Lv Z, Zhang X: Wild-Type P53 Induces Sodium/Iodide Symporter Expression Allowing Radioiodide Therapy in Anaplastic Thyroid Cancer. Cell Physiol Biochem 2017;43:905-914. 


\section{Cellular Physiology Cell Physiol Biochem 2018;50:169-178 \begin{tabular}{l|l|l} 
DOI: 10.1159/000493966 2018 & $\begin{array}{l}\text { O } 2018 \text { The Author(s). Published by S. Karger AG, Basel } \\
\text { www.karger.com/cpb }\end{array}$
\end{tabular}

10 Santoro M, Vecchio G: Thyroid cancer: a molecular perspective. Mol Cell Endocrinol 2010;321:1-2.

11 Hintzsche JD, Robinson WA, Tan AC: A Survey of Computational Tools to Analyze and Interpret Whole Exome Sequencing Data. Int J Genomics 2016;2016:7983236.

12 Li YY, Chung GT, Lui VW, To KF, Ma BB, Chow C, Woo JK, Yip KY, Seo J, Hui EP, Mak MK, Rusan M, Chau NG, Or YY, Law MH, Law PP, Liu ZW, Ngan HL, Hau PM, Verhoeft KR, Poon PH, Yoo SK, Shin JY, Lee SD, Lun SW, Jia L, Chan AW, Chan JY, Lai PB, Fung CY, Hung ST, Wang L, Chang AM, Chiosea SI, Hedberg ML, Tsao SW, van Hasselt AC, Chan AT, Grandis JR, Hammerman PS, Lo KW: Exome and genome sequencing of nasopharynx cancer identifies NF-kappaB pathway activating mutations. Nat Commun 2017;8:14121.

13 Guo M, Luo G, Jin K, Long J, Cheng H, Lu Y, Wang Z, Yang C, Xu J, Ni Q, Yu X, Liu C: Somatic Genetic Variation in Solid Pseudopapillary Tumor of the Pancreas by Whole Exome Sequencing. Int J Mol Sci 2017;18:pii: E81.

14 Lu Z, Sheng J, Zhang Y, Deng J, Li Y, Lu A, Zhang J, Yu H, Zhang M, Xiong Z, Yan H, Diplas BH, Lu Y, Liu B: Clonality analysis of multifocal papillary thyroid carcinoma by using genetic profiles. J Pathol 2016;239:7283.

15 Li H, Durbin R: Fast and accurate short read alignment with Burrows-Wheeler transform. Bioinformatics 2009;25:1754-1760.

16 Koboldt DC, Zhang Q, Larson DE, Shen D, McLellan MD, Lin L, Miller CA, Mardis ER, Ding L, Wilson RK: VarScan 2: somatic mutation and copy number alteration discovery in cancer by exome sequencing. Genome Res 2012;22:568-576.

17 Wang K, Li M, Hakonarson H: ANNOVAR: functional annotation of genetic variants from high-throughput sequencing data. Nucleic Acids Res 2010;38:e164.

18 Chang X, Wang K: wANNOVAR: annotating genetic variants for personal genomes via the web. J Med Genet 2012;49:433-436.

19 Dees ND, Zhang Q, Kandoth C, Wendl MC, Schierding W, Koboldt DC, Mooney TB, Callaway MB, Dooling D, Mardis ER, Wilson RK, Ding L: MuSiC: identifying mutational significance in cancer genomes. Genome Res 2012;22:1589-1598.

20 Wendl MC, Wallis JW, Lin L, Kandoth C, Mardis ER, Wilson RK, Ding L: PathScan: a tool for discerning mutational significance in groups of putative cancer genes. Bioinformatics 2011;27:1595-1602.

-21 Lawrence MS, Stojanov P, Polak P, Kryukov GV, Cibulskis K, Sivachenko A, Carter SL, Stewart C, Mermel CH, Roberts SA, Kiezun A, Hammerman PS, McKenna A, Drier Y, Zou L, Ramos AH, Pugh TJ, Stransky N, Helman E, Kim J et al. : Mutational heterogeneity in cancer and the search for new cancer-associated genes. Nature 2013;499:214-218.

22 Xing M: Molecular pathogenesis and mechanisms of thyroid cancer. Nat Rev Cancer 2013;13:184-199.

23 Jiang L, Chu H, Zheng H: B-Raf mutation and papillary thyroid carcinoma patients. Oncol Lett 2016;11:2699-2705.

24 Zhao H, Tang H, Huang Q, Qiu B, Liu X, Fan D, Gong L, Guo H, Chen C, Lei S, Yang L, Lu J, Bao G: MiR-101 targets USP22 to inhibit the tumorigenesis of papillary thyroid carcinoma. Am J Cancer Res 2016;6:25752586.

25 Ma B, Liao T, Wen D, Dong C, Zhou L, Yang S, Wang Y, Ji Q: Long intergenic non-coding RNA 271 is predictive of a poorer prognosis of papillary thyroid cancer. Sci Rep 2016;6:36973.

-26 Siraj AK, Masoodi T, Bu R, Beg S, Al-Sobhi SS, Al-Dayel F, Al-Dawish M, Alkuraya FS, Al-Kuraya KS: Genomic Profiling of Thyroid Cancer Reveals a Role for Thyroglobulin in Metastasis. Am J Hum Genet 2016;98:11701180.

-27 Pan W, Zhou L, Ge M, Zhang B, Yang X, Xiong X, Fu G, Zhang J, Nie X, Li H, Tang X, Wei J, Shao M, Zheng J, Yuan Q, Tan W, Wu C, Yang M, Lin D: Whole exome sequencing identifies IncRNA GAS8-AS1 and LPAR4 as novel papillary thyroid carcinoma driver alternations. Hum Mol Genet 2016;25:1875-1884.

-28 Agrawal N, Jiao Y, Sausen M, Leary R, Bettegowda C, Roberts NJ, Bhan S, Ho AS, Khan Z, Bishop J, Westra WH, Wood LD, Hruban RH, Tufano RP, Robinson B, Dralle H, Toledo SP, Toledo RA, Morris LG, Ghossein RA, Fagin JA, Chan TA, Velculescu VE, Vogelstein B, Kinzler KW, Papadopoulos N, Nelkin BD, Ball DW: Exomic sequencing of medullary thyroid cancer reveals dominant and mutually exclusive oncogenic mutations in RET and RAS. J Clin Endocrinol Metab 2013;98:E364-369.

29 Pan W, Zhou L, Ge M, Zhang B, Yang X, Xiong X, Fu G, Zhang J, Nie X, Li H, Tang X, Wei J, Shao M, Zheng J, Yuan Q, Tan W, Wu C, Yang M, Lin D: Whole exome sequencing identifies lncRNA GAS8-AS1 and LPAR4 as novel papillary thyroid carcinoma driver alternations. Hum Mol Genet 2016;25:1875-1884. 


\section{Cellular Physiology Cell Physiol Biochem 2018;50:169-178 \begin{tabular}{l|l} 
DOI: 10.1159/000493966 & and Biochemistry 2018 The Author(s). Published by S. Karger AG, Basel \\
Published online:30ctorger.com/cpb
\end{tabular}}

Fang et al.: Whole Exome Sequencing for Papillary Thyroid Cancer

-30 Xu XQ, Wang XH, Jing JX: [Advances in the research of BRAF(V600E) gene mutation correlated with papillary thyroid carcinoma]. Zhonghua Er Bi Yan Hou Tou Jing Wai Ke Za Zhi 2016;51:630-634.

-31 Czarniecka A, Oczko-Wojciechowska M, Barczynski M: BRAF V600E mutation in prognostication of papillary thyroid cancer (PTC) recurrence. Gland Surg 2016;5:495-505.

-32 Zou M, Baitei EY, Alzahrani AS, BinHumaid FS, Alkhafaji D, Al-Rijjal RA, Meyer BF, Shi Y: Concomitant RAS, RET/PTC, or BRAF mutations in advanced stage of papillary thyroid carcinoma. Thyroid 2014;24:12561266.

33 Tang KT, Lee CH: BRAF mutation in papillary thyroid carcinoma: pathogenic role and clinical implications. J Chin Med Assoc 2010;73:113-128.

34 Yang D, Zhang H, Hu X, Xin S, Duan Z: Abnormality of pl6/p38MAPK/p53/Wipl pathway in papillary thyroid cancer. Gland Surg 2012;1:33-38.

35 Beyaz S, Yilmaz OH: Molecular Pathways: Dietary Regulation of Stemness and Tumor Initiation by the PPAR-delta Pathway. Clin Cancer Res 2016;22:5636-5641.

36 Wang G, Cao R, Wang Y, Qian G, Dan HC, Jiang W, Ju L, Wu M, Xiao Y, Wang X: Simvastatin induces cell cycle arrest and inhibits proliferation of bladder cancer cells via PPARgamma signalling pathway. Sci Rep 2016;6:35783.

37 Wu K, Yang Y, Liu D, Qi Y, Zhang C, Zhao J, Zhao S: Activation of PPARgamma suppresses proliferation and induces apoptosis of esophageal cancer cells by inhibiting TLR4-dependent MAPK pathway. Oncotarget 2016;7:44572-44582.

38 Song YS, Lim JA, Park YJ: Mutation Profile of Well-Differentiated Thyroid Cancer in Asians. Endocrinol Metab (Seoul) 2015;30:252-262.

-39 Kunstman JW, Juhlin CC, Goh G, Brown TC, Stenman A, Healy JM, Rubinstein JC, Choi M, Kiss N, NelsonWilliams C, Mane S, Rimm DL, Prasad ML, Hoog A, Zedenius J, Larsson C, Korah R, Lifton RP, Carling T: Characterization of the mutational landscape of anaplastic thyroid cancer via whole-exome sequencing. Hum Mol Genet 2015;24:2318-2329.

40 Jeon MJ, Chun SM, Kim D, Kwon H, Jang EK, Kim TY, Kim WB, Shong YK, Jang SJ, Song DE, Kim WG: Genomic Alterations of Anaplastic Thyroid Carcinoma Detected by Targeted Massive Parallel Sequencing in a BRAF(V600E) Mutation-Prevalent Area. Thyroid 2016;26:683-690. 